\title{
Identificación de portadoras de distrofia muscular de Duchenne y Becker (DMD/DMB) mediante análisis de dosis génica y polimorfismos de ADN
}

\author{
Patricia Hernández, Yenny M. Gómez, Carlos M. Restrepo \\ Unidad de Genética, Instituto de Ciencias Básicas, Facultad de Medicina, Universidad del Rosario, \\ Bogotá, D.C., Colombia.
}

\begin{abstract}
Se identificaron 7 mujeres portadoras y 15 no portadoras de deleción en 16 familias con distrofia muscular de Duchenne o de Becker (DMD/DMB) mediante PCR multiplex cuantitativa y análisis de dosis génica. Los afectados con DMD/DMB mostraron deleciones en $31,25 \%$ de los casos y el estado materno de portadora se estableció por PCR multiplex cuantitativa y análisis de dosis génica. En este estudio no se observó ninguna portadora de duplicación. Tanto las mujeres portadoras de deleción como las no portadoras de 23 familias con DMD/ DMB se estudiaron con los polimorfismos intragénicos dinucleotídicos D45 y SK12, para construir haplotipos del cromosoma X; $63 \%$ de las mujeres analizadas fueron 'informativas' (heterocigotas) en este estudio. Se brindó asesoramiento genético después del análisis molecular descrito, dándoles a conocer los riesgos y los métodos de prevención de la DMD/ DMB.
\end{abstract}

Palabras clave: identificación de portadoras, dosis génica, microsatélites, STR, PCR multiplex cuantitativa, deleciones, DMD/DMB.

\section{Identification of carriers of Duchenne and Becker muscular distrophy through genic dosage and DNA polymorphism analysis}

Seven carrier and 15 non-carrier women from 16 families affected by Duchenne and Becker muscular dystrophy (DMD/DMB) were identified by quantitative PCR multiplex gene dosage. DMD/DMB patients showed $31,25 \%$ deletions and their mother carrier status was established by quantitative PCR multiplex and gene dosage analysis; no carriers of duplications were observed. $X$ chromosome haplotypes were constructed on the maternal female relatives from both deletion and no deletion patients with dinucleotide intragenic polymorphisms D45 and SK12 analysis; $63 \%$ of the women tested were informative in this study. After this molecular approach genetic counseling was given, thus contributing to their knowledge of risks and DMD/ DMB prevention methods.

Key words: carrier identification, gene dosage, microsatellites, STR, quantitative multiplex PCR, deletions, DMD/DMB

La distrofia muscular de Duchenne (DMD) es la miopatía hereditaria más común en el hombre. Afecta a uno de cada 3.500 varones nacidos vivos

\section{Correspondencia}

Patricia Hernández, Departamento de Biología, Pontificia Universidad Javeriana, Carrera 7 No.43-82, oficina 502, Bogotá, D.C. Teléfono: 320-8320, extensión 4035 y 4027. e-mail: PATHR1@Yaoo.com y patricia.javercol.javeriana. edu.co.

Recibido: 16/02/00; aceptado: 02/08/00 y se caracteriza por debilidad muscular progresiva desde la infancia, pérdida de la habilidad para caminar y muerte al final de la segunda década de vida (1-5). La distrofia muscular de Becker (DMB) es una forma alélica menos frecuente que la DMD, que presenta características clínicas menos severas y permite una mayor supervivencia (6-10). La DMD/DMB se hereda de manera recesiva ligada al sexo, aunque se ha estimado que $40 \%$ de las mutaciones son de novo; en los 
casos familiares, la madre y algunas mujeres por línea materna serán portadoras de la enfermedad y tendrán $50 \%$ de hijos afectados (11-14).

La enfermedad se debe a mutaciones del gen de la distrofina, localizado en el brazo corto del cromosoma X (Xp21), cuya secuencia contiene 2,4 Mb; está constituido por 79 exones que transcriben un ARNm de $14 \mathrm{~Kb}$ y traducen una proteína de 427 Kd y 3.685 aminoácidos (15-19). Las deleciones y duplicaciones de uno o más exones son las mutaciones más frecuentes y se presentan en $80 \%$ de los casos, mientras que el $20 \%$ restante presenta mutaciones puntuales $(1,6,15)$. En un trabajo previo, se estudiaron 28 pacientes afectados con DMD/DMB para el análisis de deleciones o duplicaciones de uno o más exones del gen de la distrofina por medio de la amplificación en tres reacciones de PCR para los siguientes exones: pm, 3, 6, 8, 12, 13, 17, 19, $43,44,45,47,48,50,51,52,60$; se observó que $39,2 \%$ de los niños colombianos afectados con DMD/DMB presentaron deleción y ninguno duplicación, hecho que ha sido informado también para nuestra población por otros autores (20-22).

El hecho de que el gen de la distrofina presente una alta tasa de mutación, aunque se puedan identificar mutaciones del tipo deleción o duplicación en los afectados de la enfermedad, hace que la identificación de mujeres portadoras de $\mathrm{DMD} / \mathrm{DMB}$ se haya convertido en un reto para los genetistas desde hace décadas. Esta información es crucial, ya que el conocimiento preciso del estado de portadora o no portadora genera expectativas y opciones frente al asesoramiento genético (23-26). El análisis del gen de la distrofina con técnicas de biología molecular ha hecho posible la identificación de madres y mujeres por línea materna portadoras de DMD/DMB. Una de las estrategias utilizadas es el análisis de dosis génica para los casos de deleción o duplicación de uno o más exones de la distrofina, utilizando la amplificación de segmentos de ADN por PCR cuantitativa $(1,27)$ y otra, la identificación indirecta del alelo mutante del gen mediante polimorfismos intragénicos $(28,29)$.

El presente estudio tiene como objetivo identificar mujeres portadoras en familias con DMD/DMB mediante el análisis de dosis génica y la identificación indirecta del alelo mutante a través del análisis de dos polimorfismos de microsatélites intragénicos, SK12 y D45.

\section{Materiales y métodos}

\section{Muestras de ADN}

La extracción de ADN genómico se realizó mediante la técnica de desalamiento $(20,21)$ a partir de $5 \mathrm{ml}$ de sangre periférica de 52 personas (23 afectados de DMD/DMB con diagnóstico clínico y de laboratorio y 29 madres o mujeres por línea materna), que aceptaron participar voluntariamente en el estudio y firmaron un consentimiento informado. Las muestras se analizaron para identificar deleciones en los afectados con DMD/DMB mediante el análisis de 6 exones estudiados previamente y el análisis de dosis génica en dúos madre-hijo afectados, en los cuales se observó deleción o duplicación de uno o más exones mediante la amplificación por PCR cuantitativa, así como en todas las familias, mediante el análisis de polimorfismos con los microsatélites intragénicos SK12 y D45.

\section{Identificación de deleciones y análisis de dosis génica por PCR cuantitativa}

Para la identificación de deleciones en los pacientes con DMD/DMB y para el análisis de dosis génica en dúos madre-hijo, se utilizaron 6 pares de iniciadores o primers marcados con Cy5, los que se amplificaron en dos subsistemas: el primero, denominado 5-plex-1, analizaba la presencia o ausencia de los exones $45,48,19,51$ y 8 , y el segundo, denominado 5-plex-2, para los exones $43,45,48,19$ y 51. Por tanto, el sistema 5-plex-1 y 5-plex-2 diferían por un solo exón. Se realizaron dos reacciones de PCR cuantitativa de manera simultánea para cada persona en un volumen final de reacción de $35 \mu \mathrm{L}$ con las siguientes concentraciones finales: $7,5 \mathrm{pM}$ de cada primer, 1,2 mM de dNTP, $3,5 \mathrm{mM}$ de $\mathrm{MgCl} 2$, $0,05 \mathrm{U} / \mu \mathrm{L}$ de Taq ADN polimerasa (Pharmacia), $1 \mathrm{X}$ de buffer y $7,1 \mathrm{ng} / \mu \mathrm{L}$ de ADN. Las muestras se amplificaron en un termociclador automático bajo el siguiente programa: desnaturaiización a $94{ }^{\circ} \mathrm{C}$ durante 30 segundos, alineamiento a $52^{\circ} \mathrm{C}$ durante 30 segundos y extensión a $65^{\circ} \mathrm{C}$ durante 
4 minutos y 20 ciclos. Se realizó una desnaturalización inicial a $94^{\circ} \mathrm{C}$ durante 7 minutos y una extensión final a $65^{\circ} \mathrm{C}$ durante 4 minutos. Luego, se verificó la presencia de productos amplificados mediante electroforesis en geles de poliacrilamida al $8 \%$.

Una vez verificada la amplificación, se realizaron electroforesis verticales en poliacrilamida en un secuenciador automático de ADN, Pharmacia AlfExpress ( ${ }^{\circledR}$. En los electroforetogramas se estableció la presencia o ausencia de los exones amplificados en los afectados; se estableció, además, el área específica para cada producto amplificado presente en los afectados y en un mínimo de dos mujeres en algunas familias con DMD/DMB que se compararon con controles normales de ambos sexos. Los cálculos de dosis génica se establecieron de acuertdo con la siguiente fórmula:

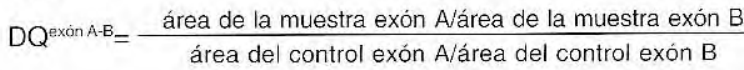
$\mathrm{DQ}^{\text {exón } \mathrm{B} \cdot \mathrm{A}}=\frac{\text { área de la muestra exón } \mathrm{B} / \text { área de la muestra exón } \mathrm{A}}{\text { área del control exón } \mathrm{B} / \text { área del control exón } \mathrm{A}}$

y teniendo en cuenta lo informado por Yau en 1996 (30).

\section{Detección de polimorfismos de microsatélites intragénicos}

Se analizaron dos polimorfismos microsatélites intragénicos, SK12 y D45, los cuales se coamplificaron conjuntamente con un control denominado NUR (que muestra un fragmento de $204 \mathrm{pb}$ ). Los primers se marcaron previamente con Cy5, con las secuencias y técnica descritas por Kochling en 1996 (31), modificada y optimizada para las condiciones de nuestro laboratorio con la siguiente mezcla de reacción: $0,6 \mathrm{pM}$ de los primers para los polimorfismos SK12 y D45; 0,4 $\mathrm{pM}$ de los primers del control NUR, 0,6 mM de dNTP; $1,5 \mathrm{mM}$ de $\mathrm{MgCl} 2 ; 0,1 \mathrm{U} / \mu \mathrm{L}$ de taq ADN polimerasa; $1 X$ de buffer y $5 \mathrm{ng} / \mu \mathrm{L}$ de ADN. Se realizaron 30 ciclos de desnaturalización a $94^{\circ} \mathrm{C}$ durante 30 segundos, alineamiento a $62^{\circ} \mathrm{C}$ durante 30 segundos y extensión a $70^{\circ} \mathrm{C}$ durante 4 minutos. Se adicionó una desnaturalización inicial a $94^{\circ} \mathrm{C}$ durante 4 minutos y una extensión final a $65^{\circ} \mathrm{C}$ durante 4 minutos. Una vez se verificó la presencia de productos amplificados, se llevaron al secuenciador de ADN para la electroforesis y el análisis posterior. Con los datos obtenidos se construyeron haplotipos para cada familia.

\section{Resultados}

\section{Identificación de mutaciones del tipo de deleción}

Se estudiaron 16 casos índice de familias con DMD/DMB mediante amplificación por PCR para 6 exones y se identificaron deleciones en 5 $(31,25 \%)$ (figuras 1 y 2$)$.

\section{Identificación de portadoras por cálculo de dosis génica}

Para realizar el análisis de dosis génica en las madres y mujeres por línea materna de los afectados con DMD/DMB, se compararon las áreas obtenidas en cada uno de los exones para el sistema de amplificación frente a controles

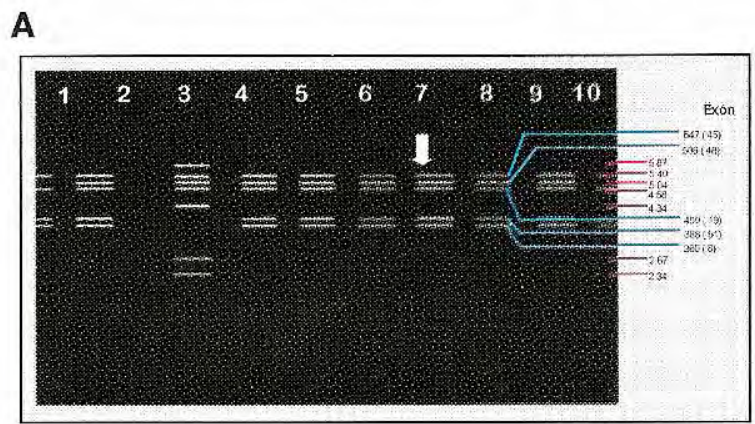

B

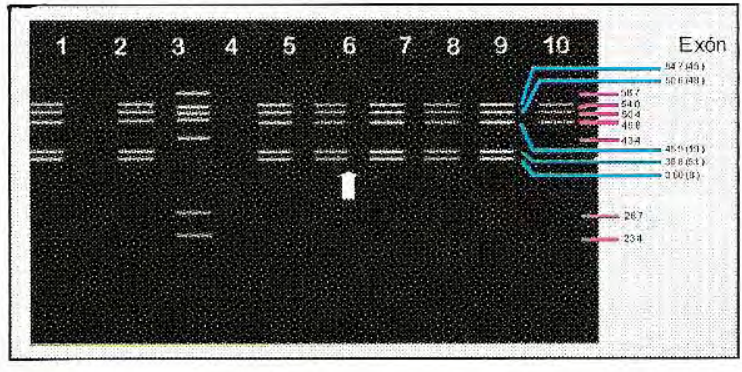

Figura 1. Electroforesis en geles de agarosa al $8 \%$ de afectados con DMD/DMB. A) Carril 7: afectado 3 con deleción del exón 48; carril 8: control sano; carril 9: blanco; carril 10: marcador de peso molecular (pBR 322 cortado con Hae III). B) Carril 6: afectado 12 con deleción del exón 8; carril 8: blanco; carril 9: control sano; carril 10: marcador de peso molecular (pBR 322 cortado con Hae III). 


\section{A}

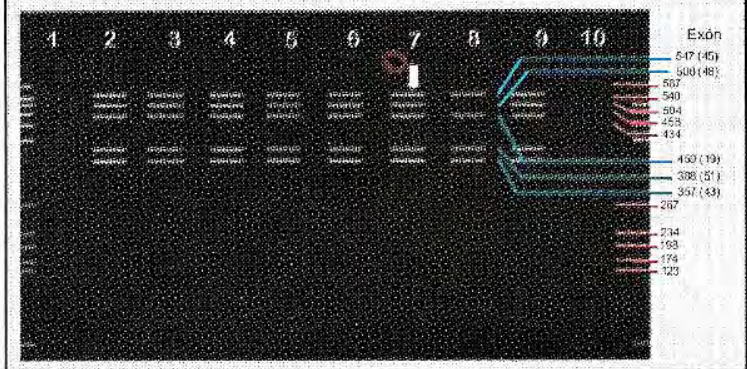

B

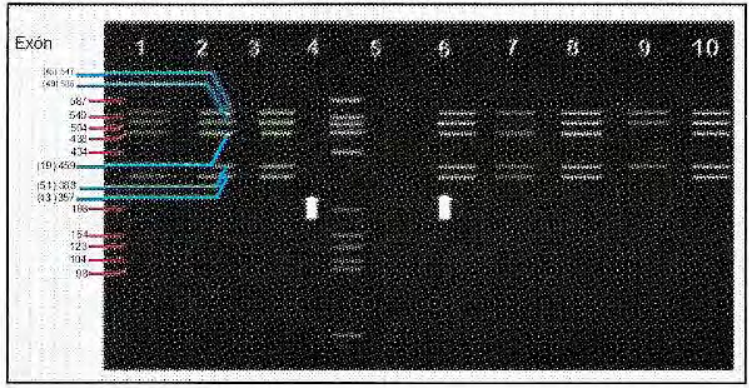

Figura 2. Electroforesis en geles de agarosa al $8 \%$ de afectados con DMD/DMB. A) Carril 1: marcador de peso molecular (pBR 322 cortado con Hae III); carril 2: blanco; carril 3: control sano; carril 4: afectado 3 con deleción del exón 48; carril 6: afectado 7 con deleción de los exones 19 y 43. B) Carril 7: afectado 24 con deleción del exón 48; carril 8: control sano; carril 9: blanco; carril 10: marcador de peso molecular (pBR 322 cortado con Hae III).

sanos, con el fin de determinar si existían mutaciones del tipo deleción o duplicación o si, por el contrario, el exon presentaba una dosis normal (cuadro 1). Mediante el cálculo de dosis génica, se identificaron 7 mujeres (30\%) como portadoras de deleción y 15 como no portadoras para los exones analizados (70\%). No se observó ninguna portadora de duplicación (cuadro 2, figura 3).

\section{Amplificación de polimorfismos de los intrones 44 y 45 del gen de la distrofina}

La amplificación del polimorfismo SK12 del intrón 44 mostró productos de amplificación comprendidos entre 177-185 pb, con alelos (CA)15 , mientras que el polimorfismo D45 del intrón 45 presentó alelos (CA) 1-10 con fragmentos entre 158$180 \mathrm{pb}$ (cuadro 3 y figura 4). En el cuadro 4 se
Cuadro 1. Fórmulas y parámetros para detección de portadoras por cálculo de dosis génica. Se utilizaron las áreas para cada exón de muestras y controles obtenidos del secuenciador de ADN. En este caso, al aplicar la fórmula se obtuvo un valor de 0,48 para el exón $45-48$, y de 2.303 para el exón 48-45. Estos valores se encuentran dentro del rango de deleción $(0,33-0,61 ; 1,56-2,88)$ establecido por Yau en 1996.

Cálculo de dosis génica (DQ)

$\mathrm{DQ}^{\mathrm{E} 55-48}=\frac{(1,612 / 4,374)}{(2,538 / 3,042}$

$D Q^{E 45 \cdot 48}=0,43$

$D Q^{E 48-45}=\frac{(4,374 / 1,612)}{(3,042 / 2,583)}$

$D^{E-48-45}=2,303$

Parámetros

\begin{tabular}{lccc}
\hline & Exón analizado & Media DQ & Rango \\
\hline Normal & 1,00 & 1,01 & $(0,77-1,27)$ \\
Deleción & 0,50 & 0,47 & $(0,33-0,61)$ \\
& 2,00 & 2,21 & $(1.56-2,88)$ \\
Duplicación & 1,50 & & \\
& 0,67 & & \\
\hline
\end{tabular}

muestra la identificación de portadoras de DMD/ DMB mediante el cálculo de dosis génica y el análisis con los polimorfismos de microsatélite SK12 y D45. Con los alelos observados para los polimorfismos SK12 y D45, se construyeron los haplotipos en las familias analizadas, como se observa en la figura 5.

\section{Discusión}

En la literatura se ha observado que entre 40 y $60 \%$ de las mutaciones del gen de la distrofina corresponde a deleciones de uno o más exones y $15 \%$, aproximadamente, corresponde a duplicaciones $(1,7,15)$. En este estudio se utilizó la combinación de 6 pares de primers en dos sistemas de amplificación, 5-plex-1 y 5-plex-2, que diferían entre sí en un solo exón. La razón por la cual el sistema 6-plex se dividió en 5-plex-1 y 5plex-2 es porque los exones 8 y 43 sólo se diferencian en tres pares de bases, hecho que dificulta la identificación de los 'amplicones' en geles de poliacrilamida. Además, con la utilización de los dos sistemas, fue posible corroborar los 
Cuadro 2. Detección de portadoras de deleción o duplicación en el gen de la distrofina por cálculo de dosis génica. El cálculo de dosis génica, se realizó con las áreas de cada exón para muestras y controles (cuadro 1), obteniéndose valores que permitieron identificar mujeres portadoras de DMD/DMB y mujeres no portadoras para los exones analizados.

\begin{tabular}{|c|c|c|c|c|c|c|c|}
\hline \multirow[b]{2}{*}{ Exón } & \multicolumn{2}{|c|}{ Pico área } & \multicolumn{5}{|c|}{ Exones DMLX 3 madre } \\
\hline & $\begin{array}{c}\text { Control } \\
900 \mathrm{E}_{2}\end{array}$ & $\begin{array}{c}\text { DMLX } 3 \\
\text { madre }\end{array}$ & 43 & 19 & 45 & 48 & 51 \\
\hline 43 & 881 & 338 & -- & 1,1 & 0,88 & 1,8 & 0,87 \\
\hline 19 & 339 & 124 & 0,95 & -- & 0,84 & 1,7 & 0,83 \\
\hline 45 & 114 & 52 & 1,1 & 1,1 & -- & 2,0 & 0,48 \\
\hline 48 & 345 & 73 & 0,55 & 0,58 & 0,48 & -- & 0,48 \\
\hline \multirow[t]{2}{*}{51} & 362 & 155 & 1,1 & 1,2 & 1,0 & 2,0 & - \\
\hline & \multicolumn{2}{|c|}{ Pico área } & \multicolumn{5}{|c|}{ Exones DMLX 7 hermana } \\
\hline Exón & $\begin{array}{c}\text { Control } \\
888 x x\end{array}$ & $\begin{array}{c}\text { DMLX } 7 \\
\text { hermana }\end{array}$ & 43 & 19 & 45 & 48 & 51 \\
\hline 43 & 327 & 129 & -- & 0,33 & 0,62 & 0,62 & 0,48 \\
\hline 19 & 140 & 191 & 2,7 & -- & 2,1 & 2,1 & 1,6 \\
\hline 45 & 126 & 80 & 1,6 & 0,46 & -- & 0,99 & 0,78 \\
\hline 48 & 170 & 108 & 1,6 & 0,47 & $1,0 \quad-$ & -- & 0,78 \\
\hline \multirow[t]{2}{*}{51} & 181 & 147 & 2,0 & 0,6 & 1,27 & 1,27 & -- \\
\hline & \multicolumn{2}{|c|}{ Pico área } & \multicolumn{5}{|c|}{ Exones DMLX 38 madre } \\
\hline Exón & Control & $\begin{array}{l}\text { DMLX } 38 \\
\text { madre }\end{array}$ & 8 & 19 & 45 & 48 & 51 \\
\hline 8 & 43 & 27 & -- & 0,59 & 1,9 & 3,0 & 1,1 \\
\hline 19 & 52 & 55 & 1,6 & -- & 2,8 & 2,8 & 1,9 \\
\hline 45 & 33 & 11 & 0,53 & 0,33 & -- & 1,7 & 0,61 \\
\hline 48 & 51 & 10 & 0,33 & 0,33 & 0,59 & -- & 0,36 \\
\hline 51 & 72 & 39 & 0,86 & 0,51 & 1,6 & 2,8 & -- \\
\hline $\begin{array}{l}\text { Exón co } \\
\text { Exón co }\end{array}$ & $\begin{array}{l}\text { opia doble } \\
\text { opia simple }\end{array}$ & $\begin{array}{c}\text { Rangos } \\
0,77-1,27 \text { norn } \\
\\
0,33-0,61 \text { det } \\
1,55-2,88 \text { det }\end{array}$ & $\begin{array}{l}\text { tección } \\
\text { tección }\end{array}$ & & $\begin{array}{l}\text { No por } \\
\text { para Ic } \\
\text { analiz } \\
\text { Portad } \\
\text { DMD/L }\end{array}$ & $\begin{array}{l}\text { rtadora } \\
\text { los exor } \\
\text { zados } \\
\text { doras d } \\
\text { DMB }\end{array}$ & \\
\hline
\end{tabular}

Cuadro 3. Fragmentos observados del polimorfismo (CA)n SK12 (Intron 44) y D45 (Intron 45) y números asignados a cada fragmento.

\begin{tabular}{cccc}
\hline \multicolumn{2}{c}{$\begin{array}{c}\text { Polimorfismos (CA)n } \\
\text { SK12 del intrón 44 }\end{array}$} & \multicolumn{2}{c}{$\begin{array}{c}\text { Polimorfismos (CA)n } \\
\text { D45 del intrón 45 }\end{array}$} \\
\hline Alelo & Tamaño (pb) & Alelo & Tamaño \\
1 & 177 & 1 & 158 \\
2 & 179 & 2 & 164 \\
3 & 181 & 3 & 166 \\
4 & 183 & 4 & 168 \\
5 & 185 & 5 & 170 \\
& & 6 & 172 \\
& & 7 & 174 \\
& & 8 & 176 \\
& & 9 & 178 \\
& & 10 & 180 \\
\hline
\end{tabular}

resultados tanto en la PCR como en las estimaciones de dosis génica, lo que ha sido sugerido por otros autores $(27,30)$. Con estos sistemas de amplificación, se detectaron deleciones en $31,25 \%$ de los casos índice, resultado similar al observado en estudios previos hechos en Colombia por nosotros y por otros autores (20-22). En este estudio se observa una baja tasa de deleciones si se le compara con estudios realizados en Norteamérica, pero es similar a la informada en trabajos realizados en poblaciones japonesas e israelitas en las que la proporción de deleciones fue de $37 \%$ (32). Igualmente, se ha informado una frecuencia mayor $(73 \%)$ en el norte de India (32). Hasta ahora, no ha sido posible explicar estas diferencias; se sugiere que se deben a diferencias en las poblaciones (32). El sistema de amplificación de 6 exones permitió establecer deleciones en un número similar de afectados a la casuística que se había informado previamente con el análisis de los sistemas 7-plex, 5-plex, 4-plex y 2-plex, en los cuales se observó una proporción total de deleciones de $39,2 \%$. Por tanto, con este sistema se identificó $92 \%$ de las deleciones que son observadas con el uso combinado de los 4 sistemas PCR-multiplex anteriores.

En la literatura clásica se ha descrito el hecho de que $80 \%$ de las deleciones o duplicaciones ocurren principalmente entre los exones 44 y 52 y el $20 \%$ restante en los exones 1 a 20 , regiones que se conocen como puntos calientes (hot spots) del gen (33). Por esta razón, los sistemas de análisis de este tipo de mutaciones del gen de la distrofina incluyen de manera preferencial esas regiones, como en efecto lo fue para los sistemas 5-plex-1 y 5-plex-2 utilizados en el presente trabajo.

Nuestros datos previos con 4 sistemas multiplex mostraron que $54,5 \%$ de las mutaciones ocurrieron en los exones 44 a 52 y el resto $(46,5 \%)$ al inicio del gen (20-22), mientras que el presente trabajo mostró una frecuencia de mutaciones en la región 44 a 52 de $60 \%$, cifras que son similares para los dos casos. Esto implica que los sistemas 5-plex1 y 5 -plex-2 pueden ser utilizados con la misma eficacia que los otros 4 sistemas multiplex, hecho que genera una reducción en el tiempo, en los procedimientos y en los costos de laboratorio, dado que se requieren sólo dos reacciones de PCR. 


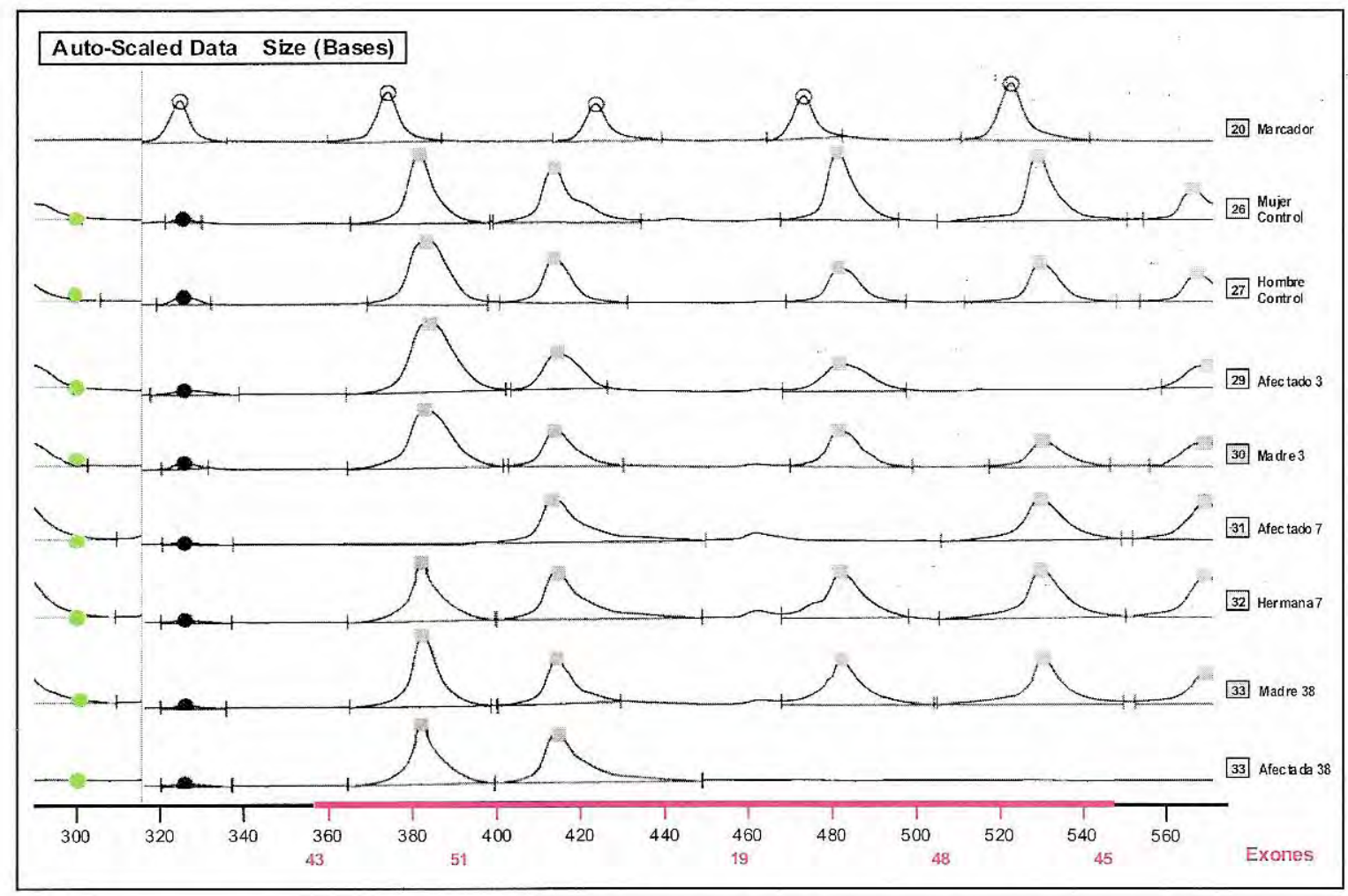

Figura 3. Electroforetograma obtenido a partir del sistema 5-plex-2 de las familias 3, 7 y 38. La ausencia de pico determina deleción en el afectado (líneas 29, 31 y 34). Por cálculo de dosis génica, las mujeres de estas familias (líneas 30,32 y 3 ) son portadoras de la enfermedad.

En los casos de DMD/DMB debidos a deleción del gen de la distrofina, se analizaron los dúos madre-hijo afectados, con el objeto de identificar si la madre era portadora obligada (presentaba deleción) o se trataba de una mutación de novo. Para ello, se requiere la amplificación de los 6 exones por medio de una PCR cuantitativa y el análisis en un secuenciador para determinar la dosis génica. Un afectado de DMD/DMB presentará ausencia de fragmento; un hombre sano tendrá una cuantificación que corresponde a una sola dosis; una mujer portadora de deleción tendrá también una dosis; una mujer sana presentará dos dosis; un afectado con duplicación de un exón tendrá dos dosis, y una mujer portadora de duplicación tendrá tres dosis del fragmento dado. Con relación al análisis de dosis génica, la extracción, cuantificación y amplificación del ADN son factores importantes para llevar a cabo la identificación de portadoras, ya que se debe colocar la misma cantidad de ADN en todas las muestras a amplificar y se debe reducir el número de ciclos de amplificación de PCR a menos de 24 (30,34-37). Por estas razones, en el presente estudio fue necesario mantener condiciones similares de extracción y cuantificación de las muestras de ADN y, además, utilizar 20 ciclos con el fin de obtener un producto amplificado controlado $(27,30)$. Dentro de los datos obtenidos en el cálculo de dosis génica, se observaron valores de deleción que se ajustan a los rangos establecidos por otros investigadores $(27,30)$, con lo cual se pudo establecer con seguridad el estado de portadora o no portadora, hecho que se confirmó en las genealogías con las mujeres que eran portadoras obligadas (figura 5). Con el análisis de dosis génica fueron analizadas 16 familias que presentaron un ADN no degradado, bien cuantificado, productos amplificados de buena calidad y resultados reproducibles, cuantificables 


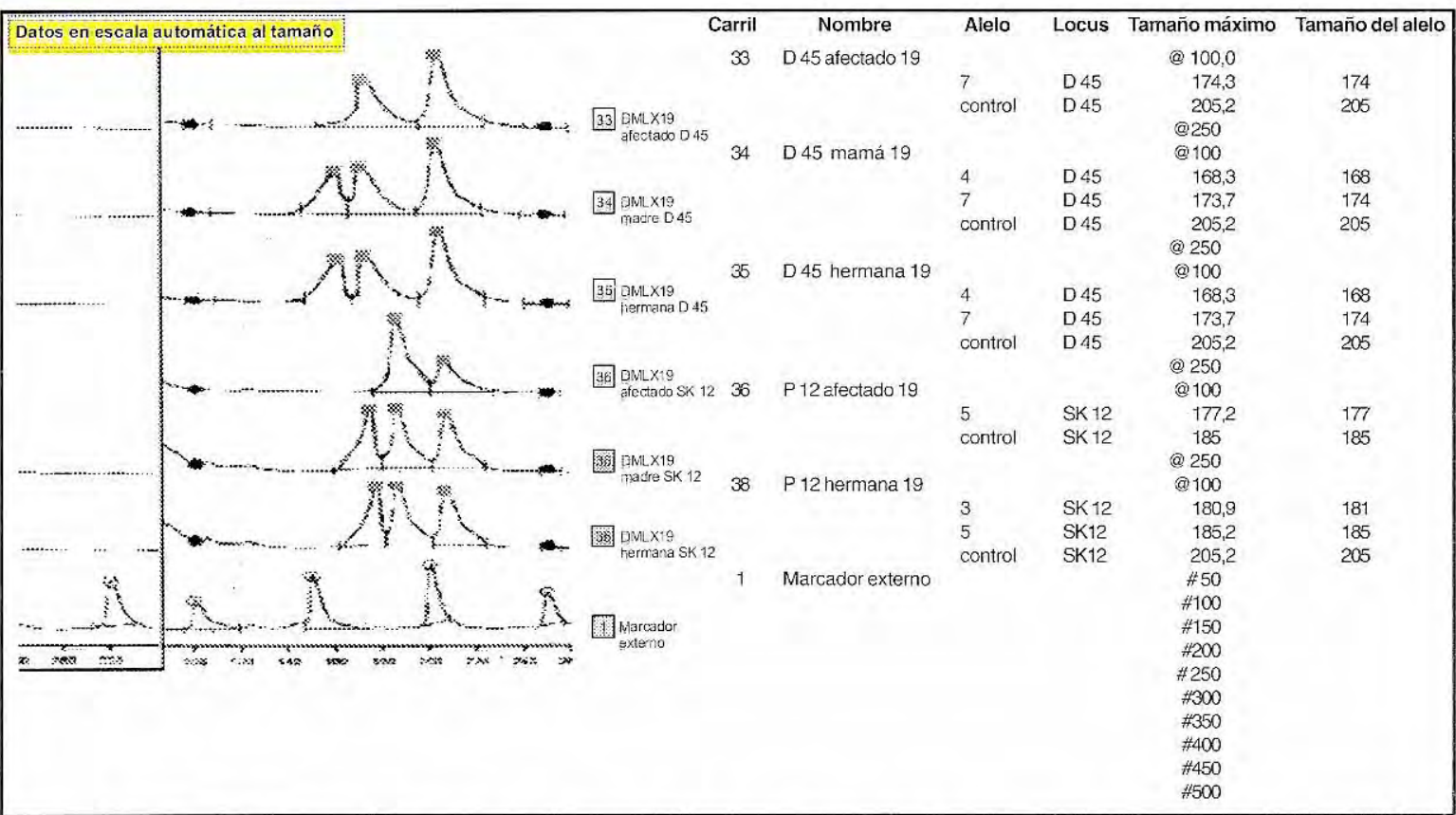

Figura 4. Electroforetograma que muestra los alelos de los polimorfismos (CA)n presentes en el gen de la distrofina de miembros de la familia 19 con un afectado por DMD. En la figura $5 \mathrm{~d}$ se observa la genealogía de la misma.

y comparables en las dos reacciones de PCR; Yau informó, en su serie de casos, que 25\% de las familias no cumplieron esas características, hecho que ocurrió en nuestro estudio en siete familias (28\%) de las 23 disponibles inicialmente para el análisis de dosis génica $(27,30)$.

El análisis mediante polimorfismos de microsatélites intragénicos de ADN mostró que el polimorfismo D45 presenta diez alelos y el polimorfismo SK12 cinco alelos en la población de dúos madre-hijo y mujeres familiares por línea materna; en otras poblaciones estos polimorfismos han mostrado 13 y 6 alelos, respectivamente (3841). La eficacia combinada de los dos polimorfismos correspondió a $63 \%$; el polimorfismo (CA)n D45 fue el más informativo con una heterocigosidad de $45 \%$, mientras que el SK 12 fue menos informativo (31\%), para las familias analizadas (cuadro 4). Este grado de eficacia se basa en que, a partir de estos polimorfismos, se identifica de manera indirecta y por ligamiento génico el alelo mutante asociado al polimorfismo observado en los afectados con DMD/DMB (figura 5). Arenas, en 1996, informó para la población mexicana $77 \%$ de efectividad en la asignación de
Cuadro 4. Detección de portadoras de DMD/DMB a través de cálculo de dosis génica y polimorfismos (CA)n .

Número de casos (29)

\begin{tabular}{lllrrr} 
Estrategia molecular & P & NP & I & NI & NA \\
\hline Cálculo dosis génica & 7 & 15 & & & 7 \\
Polimorfismo (CA)n & & & 18 & 11 & \\
SK12 & & & 9 & 20 & \\
D45 & & & 13 & 16 & \\
\hline
\end{tabular}

$\mathrm{P}$ : portadoras, NP: no portadoras, I: informativas, NI: no informativa, NA: no analizada.

portadoras utilizando cinco marcadores polimórficos, incluido el D45, el cual mostró, también en dicho estudio, la mayor heterocigosidad (29, 42-46).

En resumen, esta es la primera vez que se informa en Colombia sobre la optimización de un sistema de PCR multiplex para DMD/DMB que con solo dos reacciones y coamplificando 6 exones logra una sensibilidad similar a la obtenida en estudios previos utilizando 4 reacciones de amplificación. Igualmente, mediante el análisis de PCR cuantitativa y de dosis génica, se pudo establecer de manera confiable cuáles mujeres son portadoras o no portadoras de mutaciones del tipo 
A

DMLX 11:

II

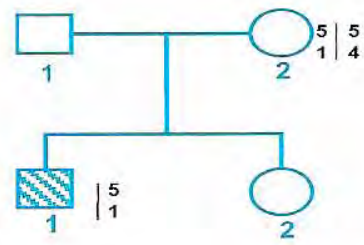

II $\triangle \Rightarrow$ Hijo afectado

C

DMLX 15:

1

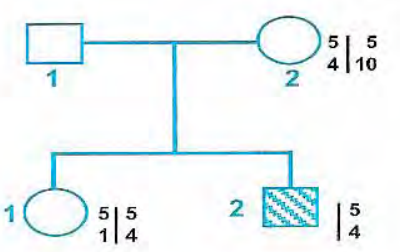

II

II $2 \Longrightarrow$ Hijo afectado
B

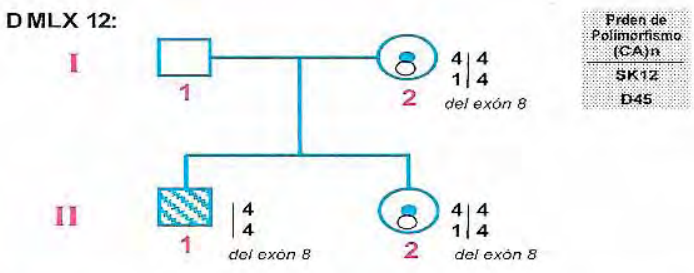

II $1 \Longrightarrow$ Hijo afectado

D

DMLX 19:

I

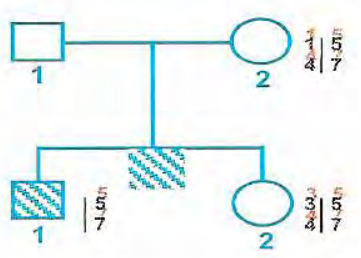

II

II $1 \Longrightarrow$ Hijo afectado

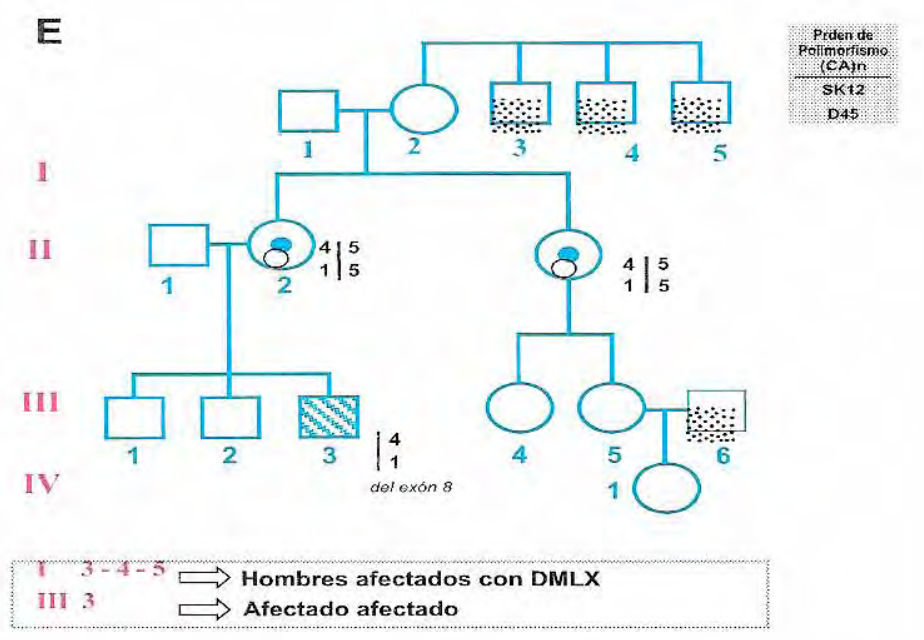

Figura 5. Arboles genealógicos de familias con DMD. A) La madre (I-2) del afectado es homocigota para el polimorfismo SK12 y heterocigota para el polimorfismo D45. El cromosoma $X$ ligado a la mutación es el que porta los alelos 5 y 1 , respectivamente. B) La madre (I-2) y hermana (II-2) del afectado son homocigotas para el polimorfismo SK12 y heterocigotas para el polimorfismo D45. El cromosoma $X$ que presenta el alelo mutante de la distrofina es el ligado a los alelos 4 y 4 , respectivamente, para SK12 y D45. Además, ambas son portadoras por cálculo de dosis génica. C) La madre (I-2) y la hermana (II-1) del afectado son homocigotas para el polimorfismo SK12 y heterocigotas para el polimorfismo D45. EI cromosoma $X$ ligado a la mutación del gen de la distrofina es el que presenta los alelos 5 y 4 , respectivamente. D) La madre (I-2) y la hermana (II-2) del afectado son heterocigotas para los dos polimorfismos. El cromosoma X ligado a la mutación del gen es el que tiene los alelos 5 y 7 , respectivamente. E) La madre (II-2) y la tía (II-3) del afectado son heterocigotas para los dos polimorfismos. El cromosoma afectado es el que porta los alelos 4 y 1 para SK12 y D45. Además, el análisis por cálculo de dosis génica mostró que son portadoras. 
deleción en las familias de afectados en quienes previamente se había identificado una deleción, hallazgos que coinciden en las familias con portadoras obligadas de la enfermedad. Finalmente, se presentan los resultados de la identificación del alelo mutante que causa DMD/ $\mathrm{DMB}$, mediante análisis de ligamiento $\mathrm{y}$ construcción de haplotipos por polimorfismos intragénicos. Más tarde se hará necesario incorporar el análisis de otros polimorfismos intragénicos al gen de la distrofina para aumentar, así, la probabilidad de identificar el alelo mutante en las familias que no sean informativas con el análisis actual, tarea que será motivo de futuros trabajos.

\section{Bibliografía}

1. Abbs S, Yau S, Clark S, Mathew CG, Bobrow M. A convenient multiplex PCR system for the detection of dystrophin gene deletions: a comparative analysis with cDNA hybridisation shows mistypings by both methods. J Med Genet 1991;28:304-11.

2. Alvarez M, Hernández PM, Perzzuno JA. Diagnóstico diferencial entre distrofia muscular de Duchenne y Becker. Gac Med Mex 1994;130:454-8.

3. Koenig A, Beggs AH, Moyer M, Scherpf S, Heindrich $\mathrm{K}$, Bettecken T, et al. The molecular basis for Duchenne versus Becker muscular dystrophy. Am J Hum Genet 1989;45:498-506

4. Kunkel L. Analysis of determination in DNA patients with Becker and Duchenne muscular dystrophy. Nature 1986;322:73-7.

5. Laing N, Siddique T, Bartlett R, Yamaoka L, Hung WY, Pericak-Vance MA, et al. Duchenne muscular dystrophy detection of deletion carriers by espectrophotometric densitometry. Clin Genet 1989;35:393-8.

6. Bakel I, Holt S, Craig I, Boyd Y. Sequence analysis of breakpoint regions of and $\mathrm{X} ; 5$ translocation in female with Duchenne muscular dystrophy. Am J Hum Genet 1996;57: 329-36.

7. Banerjee M, Verma I. Are there ethnic differences in deletions in the dystrophin gene. Am J Med Genet 1996; 68:152-7.

8. Gardner R, Bobrow M, Roberts R. Identification of points mutations in Duchenne muscular dystrophy patients by using reverse transcription, PCR and the protein truncation test. Am J Hum Genet 1995;57:311-20.

9. Fichebeck K. The difference between Duchenne and Becker dystrophies. Neurology 1989;39:584-5.

10. Shomrat R, Driks N, Legum C, Shiloh Y. Use of dystrophin genomic cDNA probes for solving difficulties in carrier detection and prenatal diagnosis of Duchennne muscular dystrophy. Am J Hum Genet 1992;42:281-7.

11. Chamberlain J, Gibbs RA, Nguyen P, Rainer J, Caskey J. Deletions screening of the Duchenne muscular dystrophy locus via multiplex DNA amplification. Nucleic Acids Res 1988;16:11141-57.

12. Clutkow J, Hyser CL, Edwars JA, Reffner R, Czymy J. Monozygotic female twin carriers discordant for the clinical manifestations of Duchenne muscular distrophy. Am J Neurol 1987;37:1147-51.

13. Gutmann DH, Fischbeck K. Molecular biology of Duchenne and Becker muscular dystrophy. Neurology 1989;26:189-94

14. Hejtmancik JF, Tsao CC, Harris SG, Ward PA, Caskey CT. Carrier diagnosis of Duchenne muscular dystrophy using RFLPs. Neurology 1986;36:1553-62.

15. Abbs S. Prenatal diagnosis of Duchenne and Becker muscular dystrophy. Prenat Diagn 1996;16:1187-98.

16. Anderson M, Kunkel L. The molecular and biochemical basis of Duchenne muscular dystrophy. TIBS 1992; 17:289-92.

17. Chamberlain F, Gibbs RA, Rainer JE, Caskey T. Diagnosis of Duchenne and Becker muscular dystrophy by polimerase chain reaction. JAMA 1992;267:2609-15.

18. Gokgoz N, Curcio C, Bresolin N, Scariato. Screening of deletion and RFLPS analysis in DMD/DMB families by PCR. Clin Genet 1993;43:261-6.

19. Ohledieck K, Matsumura K, Ionasescu V, Towbin JA, Bosch EP, Weinsteir SL, ei al. Duchenne muscular dystrophy: deficiency of dystrophin-associated proteins in the sarcolema. Neurology 1993;43:795-9.

20. Restrepo CM, Correal MC, González A, Lombo T, GómezY, Silva CT. Mutaciones en el gen de la distrofina en la distrofia muscular ligada al sexo en una población colombiana. Correlación clínico-molecular. Crónica Científica 1997;1:19-56.

21. Prieto JC, Camacho M. Caracterización de mutaciones en pacientes con distrofia muscular de Duchenne y Becker (tesis). Bogotá: Pontificia Universidad Javeriana; 1997.

22. Silva E. Informe de casos de distrofia muscular de Duchenne y Becker. Inf Quinc Epidemiol Nac 1998;3:6972.

23. Fassati A, Tedeschi S, Bordoni, Amboni P, Curcio C, Bresolin N, et al. Rapid direct diagnosis of deletions carriers of Duchenne and Becker muscular dystrophies. Lancet 1994;344:301-3.

24. Fenner C, Boyce FM, Kunkel LM. Rapid detection of CA polymorphisms in cloned DNA. Aplication to the $5^{\prime}$ region of the dystrophin gene. Am J Hum Genet 1991; 48:621-7.

25. Ioannou P, Christopoulos G, Panayides K, Kleanthous M, Middleton L. Detection of Duchenne 